\title{
The Candidate Chromosomal Regions Responsible for Milk Yield of Cow: A GWAS Meta-Analysis
}

\author{
Lida Taherkhani ${ }^{1}$, Mohammad Hossein Banabazi ${ }^{2,3, * \mathbb{C}}$, Nasser EmamJomeh-Kashan ${ }^{1}$, Alireza Noshary ${ }^{4}$ \\ and Ikhide Imumorin ${ }^{5}$
}

check for updates

Citation: Taherkhani, L.; Banabazi, M.H.; EmamJomeh-Kashan, N.; Noshary, A.; Imumorin, I. The Candidate Chromosomal Regions Responsible for Milk Yield of Cow: A GWAS Meta-Analysis. Animals 2022, 12, 582. https://doi.org/10.3390/ ani12050582

Academic Editor: Monique Rijnkels

Received: 30 December 2021 Accepted: 22 February 2022 Published: 25 February 2022

Publisher's Note: MDPI stays neutral with regard to jurisdictional claims in published maps and institutional affiliations.

Copyright: (C) 2022 by the authors. Licensee MDPI, Basel, Switzerland. This article is an open access article distributed under the terms and conditions of the Creative Commons Attribution (CC BY) license (https:// creativecommons.org/licenses/by/ $4.0 /)$.
1 Department of Animal Science, Science and Research Branch, Islamic Azad University, Tehran 1477893855, Iran; taherkhanilida2121@gmail.com (L.T.); nasser_ejk@yahoo.com (N.E.-K.)

2 Department of Biotechnology, Animal Science Research Institute of Iran (ASRI), Agricultural Research, Education \& Extension Organization (AREEO), Karaj 3146618361, Iran

3 Department of Animal Breeding and Genetics (HGEN), Center for Veterinary Medicine and Animal Science (VHC), Swedish University of Agricultural Sciences (SLU), 75007 Uppsala, Sweden

4 Department of Animal Science, Karaj Branch, Islamic Azad University, Karaj 3187644511, Iran; alireza.noshary@kiau.ac.ir

5 School of Biological Sciences, Georgia Institute of Technology, Atlanta, GA 30332, USA; igi2@biology.gatech.edu

* Correspondence: banabazi.hossein@gmail.com; Tel.: +98-9352470999

Simple Summary: Milk production is one of the most important economic traits in dairy cattle. Therefore, determining the genomic regions influencing this trait can improve milk yield. In this study, we collected data from 16 articles associated with milk yield genome-wide association studies (GWAS) on different cattle breeds. Based on the information from the analysis and level of significance $\left(p\right.$-value $\left.<2.5 \times 10^{-6}\right)$, we identified different genomic regions on chromosomes with the highest marker density, markers with the highest effect, genes within or near these regions, chromosomes with the greatest effects on milk yield.

\begin{abstract}
Milk yield (MY) is highly heritable and an economically important trait in dairy livestock species. To increase power to detect candidate genomic regions for this trait, we carried out a metaanalysis of genome-wide association studies (GWAS). In the present study, we identified 19 studies in PubMed for the meta-analysis. After review of the studies, 16 studies passed the filters for meta-analysis, and the number of chromosomes, detected markers and their positions, number of animals, and $p$-values were extracted from these studies and recorded. The final data set based on 16 GWAS studies had 353,698 cows and 3950 markers and was analyzed using METAL software. Our findings revealed 1712 significant ( $p$-value $<2.5 \times 10^{-6}$ ) genomic loci related to MY, with markers associated with MY found on all autosomes and sex chromosomes and the majority of them found on chromosome 14. Furthermore, gene ontology (GO) annotation was used to explore biological functions of the genes associated with MY; therefore, different regions of this chromosome may be suitable as genomic regions for further research into gene expression.
\end{abstract}

Keywords: candidate SNPs; dairy cattle; genome-wide association study; meta-analysis; milk yield

\section{Introduction}

Milk is an important natural source of nutrients for the growth of newborn mammals. Different methods have been applied to detect genetic factors affecting milk production in dairy cattle, the most recent of which is genome-wide association studies (GWAS). The ultimate goal of GWAS is to identify the dependency between single nucleotide polymorphisms (SNP) and a trait using high-density markers at the genome surface to detect causative mutations that affect the phenotype of a trait [1]. During the last decade, GWAS has become an important source for generating novel hypotheses in the field of 
genetics. Therefore, GWASs tend to be suitable for detecting common variants associated with specific phenotypes [2].

Using data from GWAS, the meta-analysis technique is used to detect common genomic regions affecting traits by pooling the results of many studies together. Meta-analysis is an essential tool for synthesizing evidence needed to inform clinical decision making and policy. Systematic reviews summarize available literature using specific search parameters followed by critical appraisal and logical synthesis of multiple primary studies [3]. Nowadays, the meta-analysis technique is used in the agricultural and veterinary sciences in order to resolve inconsistencies in the results of scientific sources. Using the meta-analysis technique, which is a systematic and statistical study, data from different studies can be combined to achieve a single conclusion and interpretation. The reason is that individual studies have some limitations regarding the statistical power and reliability of the results. A meta-analysis by combining data and results of different research improves statistical power and accuracy of estimates [4,5]. Meta-analysis is becoming an increasingly important tool in GWAS studies of complex genetic diseases and traits [6]. The aim of this study was to detect the chromosomal regions related to milk yield using meta-analysis of different cow breeds.

\section{Material and Methods}

\subsection{Data and Literature Review}

The review of GWAS studies on cow milk yield regarding the number of chromosomes and SNP positions reveals details of chromosomal regions that affect the trait. In this study, the data from GWAS tests on MY are from Google Scholar (https://scholar.google.ca/, accessed on 12 December 2019) and the National Center for Biotechnology Information site (www.ncbi.nlm.nih.gov, accessed on 27 December 2019) searched (Figure 1). Using different filters including articles in journals with high impact factors (greater than 0.9) and timespan 2010-2019 and also had the required factors for analysis with METAL software, 16 out of 19 studies were used for meta-analysis. The required information such as marker name and the number of their chromosomes, their position on the chromosome, their $p$-values, and also the number of tested animals of each study was stored in a file. It should be noted that the number of autosomal and sexual SNPs associated with milk yield that were extracted from these 16 articles was 3950.

Recordes identified by NCBI (PubMed) and Google Scholar searching ( $n=19$ )

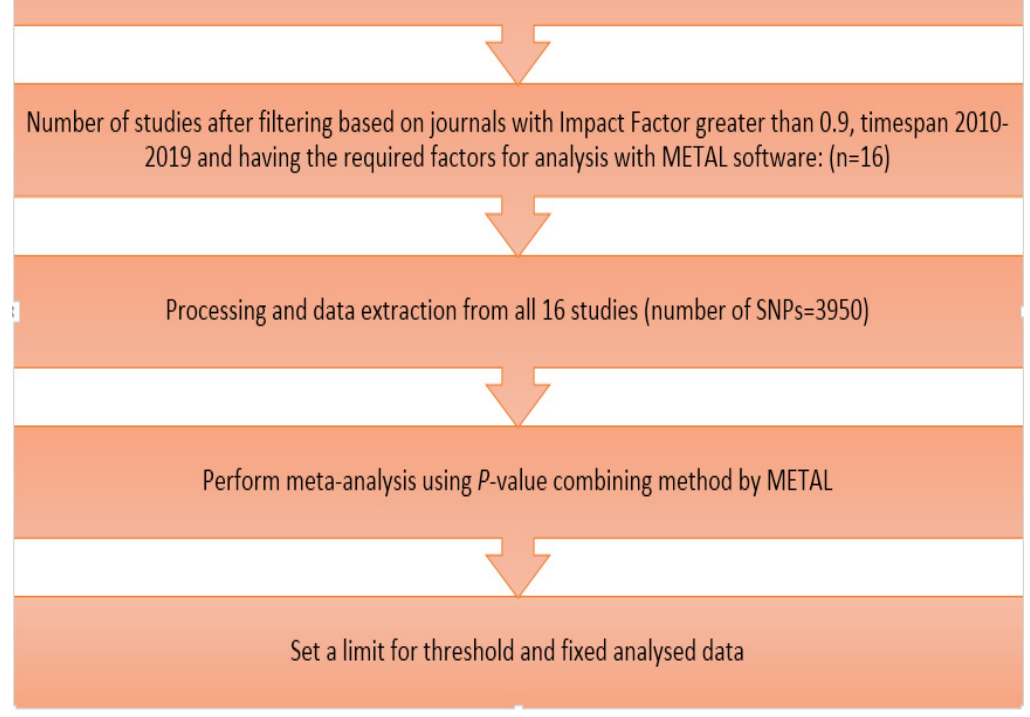

Figure 1. Flowchart of the meta-analysis of milk yield. 


\subsection{Meta-Analysis}

The meta-analysis was based on the weighted Z-scores model as implemented in the METAL software [7]. It considers the $p$-value, direction of effect, and the number of individuals included in each within-population GWAS study [8].

The GWAS meta-analysis showed the effective chromosomes (Figure 2). For the Manhattan plot, a pre-determined genome-wide significance threshold of $2.5 \times 10^{-6}$ was calculated with formulae 1 and $2(\alpha=0.01)$.

$$
\begin{gathered}
x=\frac{\alpha}{\text { NO.SNPs }} \\
-\log x=\text { threshold }
\end{gathered}
$$

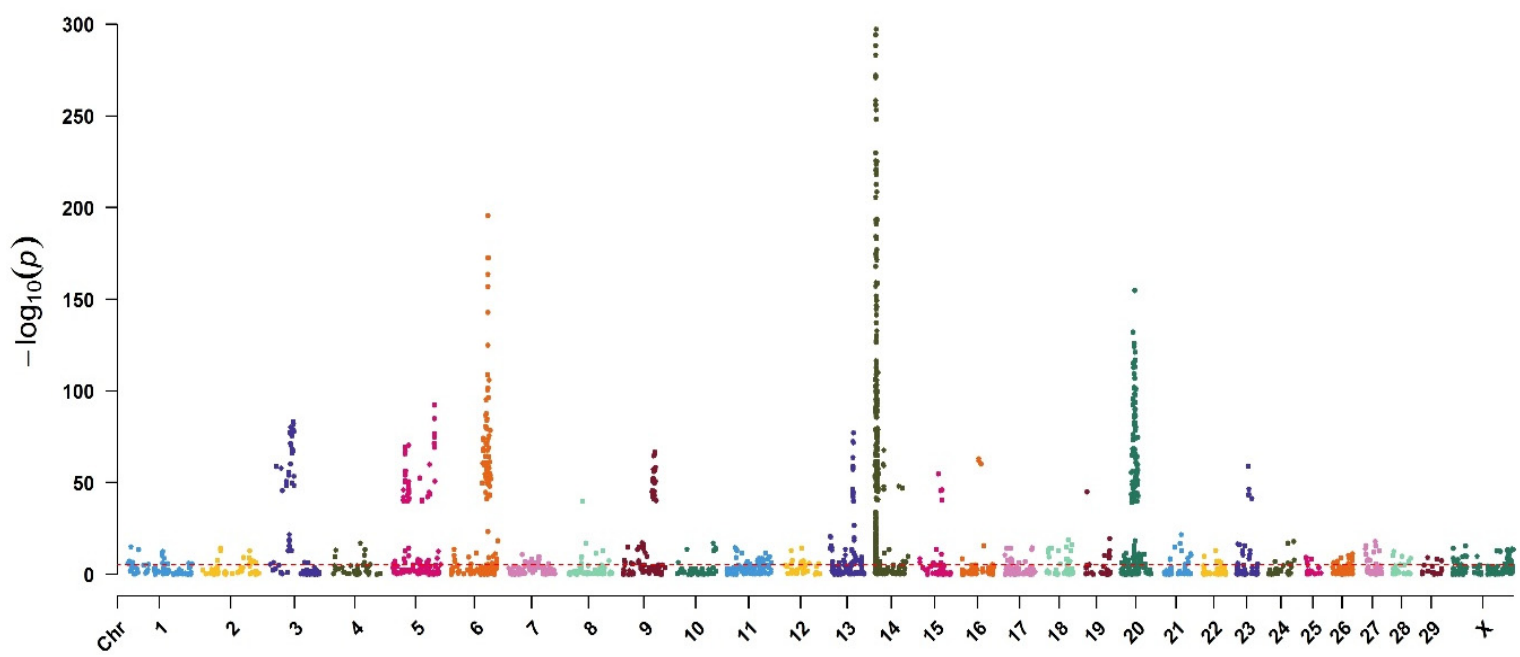

Figure 2. Manhattan plot of the GWAS meta-analysis for milk yield. Red line indicates $p=2.5 \times 10^{-6}$.

Using the Ensembl site (http:/ / ftp.ensembl.org/pub/release-103/gtf/bos_taurus/, accessed on 20 August 2020), the calculated data were checked and the loci of the effective markers and the genes were identified.

\subsection{Downstream Analyses}

The genes with variants that were significant in the meta-analysis and detected SNPs located on them were used as input for the gene ontology (GO) test. The GO terms (the significance level < 0.05) enrichment analysis with genes found within the top SNPs was performed. Using GO Consortium (https: / / biit.cs.ut.ee/gprofiler/gost, accessed on 5 February 2021), to investigate the biological processes of genes associated with MY investigated.

\section{Results}

The number of SNPs affecting the MY with a significance level lower than $<2.5 \times 10^{-6}$ were 1712 sites located on all chromosomes and mainly on chromosome 14 . The GWAS meta-analysis showed the effective chromosomes by the Manhattan plot (Figure 2). The number of effective SNPs on chromosomes 14, 20, 6, and 5 were 950, 224, 87, and 65, respectively (Table 1 ). The other 386 identified SNPs with significance levels lower than $2.5 \times 10^{-6}$ were located on the other 26 sex and autosomal chromosomes. The results showed that fifty-five percent of the effective SNPs related to milk yield were located on chromosome 14 . 
Table 1. The length of each chromosome and number of effective SNPs on them.

\begin{tabular}{|c|c|c|}
\hline CHR Number & Length (bp) & No. SNPs on CHR \\
\hline 1 & $158,337,067$ & 15 \\
\hline 2 & $137,060,424$ & 10 \\
\hline 3 & $121,430,405$ & 41 \\
\hline 4 & $120,829,699$ & 6 \\
\hline 5 & $121,191,424$ & 65 \\
\hline 6 & $119,458,736$ & 87 \\
\hline 7 & $112,638,659$ & 12 \\
\hline 8 & $113,384,836$ & 9 \\
\hline 9 & $105,708,250$ & 35 \\
\hline 10 & $104,305,016$ & 6 \\
\hline 11 & $107,310,763$ & 23 \\
\hline 12 & $91,163,125$ & 9 \\
\hline 13 & $84,2403,50$ & 45 \\
\hline 14 & $84,648,390$ & 950 \\
\hline 15 & $85,296,676$ & 13 \\
\hline 16 & $81,724,687$ & 5 \\
\hline 17 & $75,158,596$ & 13 \\
\hline 18 & $66,004,023$ & 14 \\
\hline 19 & $64,057,457$ & 12 \\
\hline 20 & $72,042,655$ & 224 \\
\hline 21 & $71,599,096$ & 10 \\
\hline 22 & $61,435,874$ & 5 \\
\hline 23 & $52,530,062$ & 17 \\
\hline 24 & $62,714,930$ & 16 \\
\hline 25 & $42,904,170$ & 13 \\
\hline 26 & $51,681,464$ & 11 \\
\hline 27 & $45,407,902$ & 11 \\
\hline 28 & $46,312,546$ & 5 \\
\hline 29 & $51,505,224$ & 3 \\
\hline \multirow[t]{2}{*}{$x$} & $148,823,899$ & 34 \\
\hline & & 1712 \\
\hline
\end{tabular}

Results for the top loci by $p$-value in the meta-analysis, with the most significant SNP per locus, are presented in (Table 2). The significance level of 1712 identified SNPs in the meta-analysis was compared and 5 SNPs of rs109421300, rs135549651, rs109146371, rs109350371, and BovineHD4100003579 had the smallest $p$-values (Table 2).

Table 2. The detailed information of top 50 detected SNPs via meta-analysis in milk yield.

\begin{tabular}{ccccc}
\hline CHR Number & SNP Name & Position & Overlapped Genes & $p$-Value \\
\hline 14 & rs109421300 & 1801116 & DGAT1 & $2.93 \times 10^{-771}$ \\
14 & rs135549651 & 1967325 & ENSBTAG00000015040 & $1.12 \times 10^{-710}$ \\
14 & rs109146371 & 1651311 & & $1.82 \times 10^{-653}$ \\
14 & rs109350371 & 2054457 & & $1.90 \times 10^{-637}$ \\
5 & BovineHD410000357 & 32784231 & RPAP3 & $3.10 \times 10^{-416}$ \\
14 & rs109558046 & 2909929 & & $1.44 \times 10^{-396}$ \\
14 & rs109752439 & 1489496 & & $1.17 \times 10^{-366}$ \\
14 & rs110199901 & 2524432 & & $4.10 \times 10^{-298}$ \\
14 & rs110706284 & 2398876 & ZC3H3 & $6.76 \times 10^{-295}$ \\
14 & rs41627764 & 2276443 & & $5.13 \times 10^{-289}$ \\
14 & rs41629750 & 2002873 & & $6.61 \times 10^{-284}$ \\
14 & rs137205809 & 1892559 & MROH1 & $6.36 \times 10^{-273}$ \\
14 & rs137787931 & 1880378 & MROH1 & $1.44 \times 10^{-272}$ \\
14 & rs133119726 & 1868636 & MROH1 & $9.39 \times 10^{-272}$ \\
\hline
\end{tabular}


Table 2. Cont.

\begin{tabular}{|c|c|c|c|c|}
\hline CHR Number & SNP Name & Position & Overlapped Genes & $p$-Value \\
\hline 14 & rs109742607 & 2217163 & & $4.47 \times 10^{-259}$ \\
\hline 14 & rs41256919 & 1923292 & MAF1 & $3.28 \times 10^{-257}$ \\
\hline 14 & rs110323635 & 2239085 & MAPK15 & $9.29 \times 10^{-257}$ \\
\hline 14 & rs109529219 & 2468020 & RHPN1 & $5.37 \times 10^{-254}$ \\
\hline 14 & rs110060785 & 2553525 & & $6.91 \times 10^{-249}$ \\
\hline 14 & rs17870736 & 1696470 & VPS28 & $1.86 \times 10^{-230}$ \\
\hline 14 & rs110892754 & 2117455 & & $2.82 \times 10^{-226}$ \\
\hline 14 & rs109086264 & 4414829 & TRAPPC9 & $7.94 \times 10^{-226}$ \\
\hline 14 & rs110174651 & 2754909 & & $3.71 \times 10^{-224}$ \\
\hline 14 & rs136891853 & 2764862 & & $2.95 \times 10^{-221}$ \\
\hline 14 & rs110749653 & 2138926 & ENSBTAT00000065585 & $3.89 \times 10^{-221}$ \\
\hline 14 & rs110411273 & 3640788 & & $1.20 \times 10^{-219}$ \\
\hline 14 & rs110626984 & 2674264 & & $8.13 \times 10^{-219}$ \\
\hline 14 & rs29024688 & 3297177 & & $2.57 \times 10^{-213}$ \\
\hline 14 & rs55617160 & 4468478 & TRAPPC9 & $3.02 \times 10^{-209}$ \\
\hline 14 & rs134974438 & 2150825 & & $2.63 \times 10^{-206}$ \\
\hline 6 & rs110527224 & 88592295 & & $3.23 \times 10^{-196}$ \\
\hline 14 & rs110143087 & 4767039 & & $1.51 \times 10^{-194}$ \\
\hline 14 & rs109530164 & 4456595 & TRAPPC9 & $2.40 \times 10^{-194}$ \\
\hline 14 & rs137757978 & 2164419 & & $6.16 \times 10^{-194}$ \\
\hline 14 & rs109225594 & 4848750 & & $1.00 \times 10^{-193}$ \\
\hline 14 & rs109545018 & 3006509 & ADGRB1 & $6.81 \times 10^{-192}$ \\
\hline 14 & rs109968515 & 1675278 & CYHR1 & $5.37 \times 10^{-185}$ \\
\hline 14 & rs110251237 & 4068825 & & $1.70 \times 10^{-184}$ \\
\hline 14 & rs110185345 & 4043743 & PTK2 & $4.90 \times 10^{-184}$ \\
\hline 14 & rs111018678 & 4336714 & TRAPPC9 & $7.76 \times 10^{-178}$ \\
\hline 14 & rs137309662 & 3371507 & & $2.57 \times 10^{-176}$ \\
\hline 14 & rs135270011 & 2084067 & PLEC & $2.82 \times 10^{-175}$ \\
\hline 14 & rs108992746 & 2951045 & ADGRB1 & $7.76 \times 10^{-174}$ \\
\hline 6 & rs137147462 & 88887995 & & $2.63 \times 10^{-173}$ \\
\hline 6 & rs110694875 & 89139865 & & $2.75 \times 10^{-173}$ \\
\hline 14 & rs110017379 & 4364952 & TRAPPC9 & $4.07 \times 10^{-172}$ \\
\hline 14 & rs41602530 & 2194228 & SCRIB & $1.66 \times 10^{-168}$ \\
\hline 6 & rs42766480 & 88891318 & & $2.82 \times 10^{-164}$ \\
\hline 14 & rs719209105 & 2741434 & GML & $8.32 \times 10^{-160}$ \\
\hline 14 & rs110501942 & 5494654 & FAM135B & $1.74 \times 10^{-159}$ \\
\hline
\end{tabular}

The identified SNPs were distributed on 18 genes (regardless of duplicate genes) with the names: DGAT1, ENSBTAG00000015040, RPAP3, ZC3H3, MROH1, MAF1, MAPK15, RHPN1, VPS28, TRAPPC9, ENSBTAT00000065585, ADGRB1, CYHR1, PTK2, PLEC, SCRIB, GML, and FAM135B.

The GO annotation based on biological processes (BP) showed 32 genes involved in biological functions associated with MY. According to the GO term, these candidate genes were found to be enriched in 15 biological processes. All of GO terms for MYrelated biological pathways were related to "wound healing", "metaphase/anaphase transition of meiosis I", "meiotic chromosome separation", "cell migration", "cell motility and locomotion" (Table 3).

The 18 candidate genes for MY resulting from GWAS were associated with the GO terms of PTK2 (wound healing) also in (response to wounding), ENSBTAT00000065585 (wound healing, response to wounding, negative regulation of cellular component movement, intermediate filament cytoskeleton organization, intermediate filament-based process, negative regulation of locomotion, negative regulation of cell migration, negative regulation of cell motility), SCRIB (wound healing, response to wounding, vesicle targeting, neurotransmitter receptor transport postsynaptic membrane to endosome), MAPK15 (vesi- 
cle targeting, positive regulation of metaphase/anaphase transition of meiosis I, regulation of metaphase/anaphase transition of meiosis I, positive regulation of meiotic chromosome separation, positive regulation of metaphase/anaphase transition of meiotic cell cycle, negative regulation of cellular component movement, negative regulation of locomotion, negative regulation of cell migration, metaphase/anaphase transition of meiosis I, negative regulation of cell motility), ADGRB1 (negative regulation of cellular component movement, negative regulation of locomotion, negative regulation of cell migration, negative regulation of cell motility), and PLEC (wound healing, response to wounding, intermediate filament cytoskeleton organization, intermediate filament-based process).

Table 3. Significant biological process associated with genes affecting milk yield.

\begin{tabular}{|c|c|c|c|c|}
\hline Term ID & Term Name & $p$-Value (Adj) & Gene Name & Number \\
\hline GO:0042060 & Wound healing & 0.033647963 & $\begin{array}{l}\text { ENSBTAT00000065585, PTK2, } \\
\text { PLEC, SCRIB }\end{array}$ & 4 \\
\hline GO:0009611 & Response to wounding & 0.039101239 & $\begin{array}{l}\text { ENSBTAT00000065585, PTK2, } \\
\text { PLEC, SCRIB }\end{array}$ & 4 \\
\hline GO:0006903 & Vesicle targeting & 0.048695181 & MAPK15, SCRIB & 2 \\
\hline GO:1905188 & $\begin{array}{l}\text { Positive regulation of metaphase/anaphase } \\
\text { transition of meiosis I }\end{array}$ & 0.048695181 & MAPK15 & 1 \\
\hline GO:1905186 & $\begin{array}{c}\text { Regulation of metaphase/anaphase } \\
\text { transition of meiosis I }\end{array}$ & 0.048695181 & MAPK15 & 1 \\
\hline GO:1905134 & Positive regulation of meiotic chromosome separation & 0.048695181 & MAPK15 & 1 \\
\hline GO:1902104 & $\begin{array}{c}\text { Positive regulation of metaphase/anaphase } \\
\text { transition of meiotic cell cycle }\end{array}$ & 0.048695181 & MAPK15 & 1 \\
\hline GO:0098968 & $\begin{array}{l}\text { Neurotransmitter receptor transport postsynaptic } \\
\text { membrane to endosome }\end{array}$ & 0.048695181 & SCRIB & 1 \\
\hline GO:0051271 & Negative regulation of cellular component movement & 0.048695181 & $\begin{array}{l}\text { MAPK15, ENSBTAT00000065585, } \\
\text { ADGRB1 }\end{array}$ & 3 \\
\hline GO:0045104 & Intermediate filament cytoskeleton organization & 0.048695181 & ENSBTAT00000065585, PLEC & 2 \\
\hline GO:0045103 & Intermediate filament-based process & 0.048695181 & ENSBTAT00000065585, PLEC & 2 \\
\hline GO:0040013 & Negative regulation of locomotion & 0.048695181 & $\begin{array}{l}\text { MAPK15, ENSBTAT00000065585, } \\
\text { ADGRB1 }\end{array}$ & 3 \\
\hline GO:0030336 & Negative regulation of cell migration & 0.048695181 & $\begin{array}{l}\text { MAPK15, ENSBTAT00000065585, } \\
\text { ADGRB1 }\end{array}$ & 3 \\
\hline GO:1990949 & Metaphase/anaphase transition of meiosis I & 0.048695181 & MAPK15 & 1 \\
\hline GO:2000146 & Negative regulation of cell motility & 0.048695181 & $\begin{array}{l}\text { MAPK15, ENSBTAT00000065585, } \\
\text { ADGRB1 }\end{array}$ & 3 \\
\hline
\end{tabular}

Note: GO enrichment analysis was performed in candidate genes associated with milk yield $\left(p\right.$-value $\left.<2.5 \times 10^{-6}\right)$.

\section{Discussion}

A genome-wide meta-analysis and enrichment analysis for milk yield was conducted according to the results of 16 studies (on 353,698 cows and 3950 SNPs) from all over the world (Table 4). We confirmed substantial contribution of different chromosomal loci associated with MY in cows. Three of the most important SNPs, i.e., rs109421300, rs135549651, and rs109146371, were located on chromosome 14.

Table 4. Identified SNPs on each continent. Data extracted from scientific literature published from 2010 to 2019.

\begin{tabular}{ccccc}
\hline Continent & Studies & $\mathbf{N}^{\mathbf{1}}$ & No. SNPs $^{\mathbf{2}}$ & Refs. \\
\hline Africa & 1 & 250 & 20 & {$[9]$} \\
Asia & 5 & 13,188 & 74 & {$[10-14]$} \\
Europe & 5 & 22,384 & 1542 & {$[15-19]$} \\
North America & 4 & 299,951 & 2309 & {$[20-23]$} \\
Australia & 1 & 17,925 & 5 & {$[24]$} \\
\hline Global & 16 & 353,698 & 3950 &
\end{tabular}

${ }^{1} \mathrm{~N}$, number of animals tested; ${ }^{2}$ no. SNPs, number of detected SNPs on cows in each continent.

These observations support the notion that the suggestive loci identified in this study, have an outstanding effect on MY. Moreover, fifty-five percent or 995 identified SNPs with a 
significance level lower than the specified level, were located on chromosome 14. Therefore, it can be concluded that chromosome 14 is the most effective chromosome on MY. The description of its different regions adds to the accuracy of this issue.

The study showed that regions 1,489,496 to 5,494,654 of chromosome 14 had the most effective SNPs compared to other regions of this chromosome. This means that all of the top 45 SNPs on chromosome 14 were located in this region. Only 24 SNPs in this region were located on the genes. Given that, the density of markers in some regions, including $1,675,278$ to $1,967,325$ and $4,336,714$ to $4,468,478$, was higher than in other regions, so that 13 SNPs from 45 of them were located on these regions and the most influential SNP ( $p$-value: $2.93 \times 10^{-771}$ ) in this region was on DGAT1 (Diacylglycerol O-Acyltransferase 1), a protein-coding gene. DGAT1 is an enzyme that catalyzes the synthesis of triglycerides from diglycerides and acyl-coenzyme A [25]. The DGAT1 K232A polymorphism was previously shown to have a significant effect on bovine milk production characteristics (milk yield, protein content, fat content, and fatty acid composition) [25]. The next SNP ( $p$-value: $1.12 \times 10^{-710}$ ) was located on the LOC100141215 gene. Therefore, because these regions have the highest density and the greatest effect, it can be said, the regions with the most impact.

In our study, a gene-set enrichment analysis and a group of GO enriched for MY were related to several traits. More accurate results showed the GO_BP: 0,042,060 (wound healing), GO_BP: 0,009,611 (response to wounding), GO_BP: 0,006,903 (vesicle targeting), GO_BP: 1,905,188 (positive regulation of metaphase/anaphase transition of meiosis I), GO_BP: 1,905,186 (regulation of metaphase/anaphase transition of meiosis I), GO_BP: 1,905,134 (positive regulation of meiotic chromosome separation), GO_BP: 1,902,104 (positive regulation of metaphase/anaphase transition of meiotic cell cycle), GO_BP: 0,098,968 (neurotransmitter receptor transport postsynaptic membrane to endosome), GO_BP: 0,051,271 (negative regulation of cellular component movement), GO_BP: 0,045,104 (intermediate filament cytoskeleton organization), GO_BP: 0,045,103 (intermediate filament-based process), GO_BP: 0,040,013 (negative regulation of locomotion), GO_BP: 0,030,336 (negative regulation of cell migration), GO_BP: 1,990,949 (metaphase/anaphase transition of meiosis I), GO_BP: 2,000,146 (negative regulation of cell motility).

In the continuation of this study, for a better understanding of the mechanisms of MY and the genomic regions involved, it was necessary to analyze the candidate regions obtained from the results of this study. After performing downstream analyses and finding the relation between the identified genes and these terms, we investigated the relation between some of them and MY using studies that have been previously conducted.

Wound healing is a localized process that involves inflammation, wound cell migration and mitosis, neovascularization, and regeneration of the extracellular matrix [26]. Milk of the cow, especially low-fat milk, is a rich source of calcium which can play a significant role in the acceleration of wound healing and increment of healing quality [27]. Calcium has an essential role in wound healing; therefore, healing is known as a calcium-dependent process [27].

The metaphase to anaphase transition is a point of no return; the duplicated sister chromatids segregate to the future daughter cells, and any mistake in this process may be deleterious to progeny [28]. The metaphase to anaphase transition is controlled by a ubiquitin-mediated degradation process [28].

Cell migration is a complex process requiring the coordination of numerous interand intracellular events, such as cytoskeleton reorganization, matrix remodeling, cell-cell adhesion modulation, and induction of chemoattractants [29]. Cell migration plays an important role in a variety of normal physiological processes. These include embryogenesis, angiogenesis, wound healing, repairing of intestinal mucosal damage, and immune defense [30]. However, in some pathological conditions, such as atherosclerosis or gastrointestinal ulcers, a large area of denudation is commonly found, and an immediate repair by the reestablishment of the intact monolayer of cells is required [31]. 
Cell motility is the capacity of cells to translocate onto a solid substratum. This behavior is often a hallmark of fibroblastic cells. In epithelial cells, cell motility occurs after the dissociation of a cell from its neighboring cell(s) and after the modification of its position relative to other cells or a solid substrate [32]. Cell motility plays an integral role in many physiologic and pathologic processes, notably organized wound contraction and fibroblast and vascular endothelial cell migration during wound healing, metastatic tumor cell migration, stem cell mobilization and homing, and tissue remodeling [33]. Sufficient information is not available about other terms and their relation to MY and this requires further investigation.

For a better understanding of the mechanisms of milk production, it is suggested that more downstream analysis on the proposed region affecting MY including pathway analysis is carried out. Furthermore, it may be needed to review the contribution of the genes located in that region on the MY variance. For example, DGAT1, which is a major gene for MY, had the highest significant level in this study. Banabazi et al. (2016) have identified SNPs located on the transcribed regions and their $100 \mathrm{~K}$ proposed panel performed $2 \%$ better than the $700 \mathrm{~K}$ panel [34]. It is suggested to check the SNPs located on the candidate region among 1019 loci that they discovered on the transcriptome of chromosome 14 and 24,842 SNPs located on a high-density commercial SNP array (700 K) on the same chromosome. In addition, the comparison between Bos-taurus and Bos-indicus cattle may highlight the importance of the candidate region.

\section{Conclusions}

The most effective SNPs and genes which affect milk yield are located on chromosome 14, and the regions between 1,489,496 to 5,494,654 have the most effective SNPs in terms of the significance level. Emphasis on the use of these SNPs could justify a large part of the genetic variance in MY. Downstream analyses in these regions also partially demonstrated the mechanism of the effect of genes associated with MY in these regions. Additional analysis can help better understand the mechanism of MY in these regions.

Author Contributions: Conceptualization, M.H.B.; Methodology, L.T. and M.H.B.; Software, L.T.; Validation, M.H.B., N.E.-K., A.N. and I.I.; Formal analysis, M.H.B.; Investigation, L.T.; Resources, M.H.B.; Data curation, L.T. and M.H.B.; Writing-original draft preparation, L.T.; Writing-review \& editing, M.H.B., N.E.-K., A.N. and I.I.; Visualization, L.T.; Supervision, M.H.B., N.E.-K., A.N. and I.I.; Project administration, M.H.B., N.E.-K., A.N. and I.I. All authors have read and agreed to the published version of the manuscript.

Funding: This research received no external funding.

Acknowledgments: This research was conducted with the support of Animal Science Research Institute of Karaj, Iran. We would like to thank Morteza Bitaraf Sani from Animal Science Research Department in Yazd, Iran, and also Siavash Salek Ardestani for their technical assistance.

Conflicts of Interest: The authors declare no conflict of interest.

\section{References}

1. Goddard, M.E.; Hayes, B.J. Mapping genes for complex traits in domestic animals and their use in breeding programmes. Nat. Rev. Genet. 2009, 10, 381-391. [CrossRef] [PubMed]

2. Visscher, P.M.; Brown, M.A.; McCarthy, M.I.; Yang, J. Five years of GWAS discovery. Am. J. Hum. Genet. 2012, 90, 7-24. [CrossRef] [PubMed]

3. Gopalakrishnan, S.; Ganeshkumar, P. Systematic reviews and metaanalysis: Understanding the best evidence in primary healthcare. J. Fam. Med. Prim. 2013, 2, 9-14.

4. Ramasamy, A.; Mondry, A.; Holmes, C.C.; Altman, D.G. Key issues in conducting a meta-analysis of gene expression microarray datasets. PLoS Med. 2008, 5, e184. [CrossRef]

5. Sharifi, S.; Pakdel, A.; Ebrahimi, M.; Reecy, J.M.; Fazeli Farsani, S.; Ebrahimie, E. Integration of machine learning and meta-analysis identifies the transcriptomic bio-signature of mastitis disease in cattle. PLoS ONE 2018, 13, e0191227. [CrossRef] [PubMed]

6. De Bakker, P.I.W.; Ferreira, M.A.R.; Jia, X.; Neale, B.M.; Raychaudhuri, S.; Voight, B.F. Practical aspects of imputation-driven meta-analysis of genome-wide association studies. Hum. Mol. Genet. 2008, 17, R122-R128. [CrossRef] 
7. Willer, C.J.; Li, Y.; Abecasis, G.R. METAL: Fast and efficient meta-analysis of genomewide association scans. Bioinformatics 2010, 26, 2190-2191. [CrossRef]

8. Van den Berg, I.; Xiang, R.; Jenko, J.; Pausch, H.; Boussaha, M.; Schrooten, C.; Tribout, T.; Gjuvsland, A.B.; Boichard, D.; Nordbø, O.; et al. Meta-analysis for milk fat and protein percentage using imputed sequence variant genotypes in 94,321 cattle from eight cattle breeds. Genet. Sel. Evol. 2020, 52, 37. [CrossRef]

9. El-Halawany, N.; Abdel-Shafy, H.; Shawkya, A.E.M.A.; Abdel-Latif, M.A.; Al-Tohamy, A.F.M.; Abd El-Moneim, O.M. Genomewide association study for milk production in Egyptian buffalo. Livest. Sci. 2017, 198, 10-16. [CrossRef]

10. Yodklaew, P.; Koonawootrittriron, S.; Elzo, M.A.; Suwanasopee, T.; Laodim, T. Genome-wide association study for lactation characteristics, milkyield and age at first calving in a Thai multibreed dairy cattle population. Agric. Nat. Resour. 2017, 51, 223-230.

11. Jiang, L.; Liu, J.; Sun, D.; Ma, P.; Ding, X.; Yu, Y.; Zhang, Q. Genome wide association studies for milk production traits in chinese holstein population. PLOS ONE 2010, 5, e13661. [CrossRef] [PubMed]

12. Ning, C.; Wang, D.; Zheng, X.; Zhang, Q.; Zhang, S.; Mrode, R.; Liu, J.F. Eigen decomposition expedites longitudinal genome-wide association studies for milk production traits in Chinese Holstein. Genet. Sel. Evol. 2018, 50, 12. [CrossRef] [PubMed]

13. Yue, S.J.; Zhao, Y.Q.; Gu, X.R.; Yin, B.; Jiang, Y.L.; Wang, Z.H.; Shi, K.R. A genome-wide association study suggests new candidate genes for milk production traits in Chinese Holstein cattle. Anim. Genet. 2017, 48, 677-681. [CrossRef] [PubMed]

14. Jiang, L.; Liu, X.; Yang, J.; Wang, H.; Jiang, J.; Liu, L.; He, S.; Ding, X.; Liu, J.; Zhang, Q. Targeted resequencing of GWAS loci reveals novel genetic variants for milk production traits. BMC Genom. 2014, 15, 1105. [CrossRef] [PubMed]

15. Meredith, B.K.; Kearney, F.J.; Finaly, E.K.; Bradly, D.G.; Fahey, A.G.; Berry, D.P.; Lynn, D.J. Genome-wide associations for milk production and somatic cell score in Holstein-Friesian cattle in Ireland. BMC Genet. 2012, 13, 21. [CrossRef]

16. Iso-Touru, T.; Sahana, G.; Guldbrandtsen, B.; Lund, M.S.; Vilkki, J. Genome-wide association analysis of milk yield traits in Nordic Red Cattle using imputed whole genome sequence variants. BMC Genet. 2016, 17, 55. [CrossRef]

17. Fang, L.; Sahana, G.; Su, G.; Yu, Y.; Zhang, S.; Lund, M.S.; Sorensen, P. Integrating sequence-based GWAS and RNA-Seq provides novel insights into the genetic basis of mastitis and milk production in dairy cattle. Sci. Rep. 2017, 7, 45560. [CrossRef]

18. Guo, J.; Jorjani, H.; Carlborg, O. A genome-wide association study using international breeding-evaluation data identifies major loci affecting production traits and stature in the Brown Swiss cattle breed. BMC Genet. 2012, 13, 82. [CrossRef]

19. Deng, T.; Liang, A.; Liang, S.; Ma, X.; Lu, X.; Duan, A.; Pang, C.; Hua, G.; Liu, S.; Campanile, G.; et al. Integrative analysis of transcriptome and GWAS data to identify the hub genes associated with milk yield trait in buffalo. Front. Genet. 2019, 10, 36. [CrossRef]

20. Liu, J.J.; Liang, A.X.; Campanile, G.; Plastow, G.; Zhang, C.; Wang, Z.; Salzano, A.; Gasparrini, B.; Cassandro, M.; Yang, L.G. Genome-wide association studies to identify quantitative trait loci affecting milk production traits in water buffalo. J. Dairy Sci. 2018, 101, 433-444. [CrossRef]

21. Jiang, J.; Ma, L.; Prakapenka, D.; VanRaden, P.M.; Cole, J.B.; Da, Y. A large-scale genome-wide association study in U.S. Holstein cattle. Front. Genet. 2019, 10, 412. [CrossRef] [PubMed]

22. Nayeri, S.; Sargolzaei, M.; Abo-Ismail, M.K.; May, N.; Miller, S.P.; Schenkel, F.; Moore, S.S.; Stothard, P. Genome-wide association for milk production and female fertility traits in Canadian dairy Holstein cattle. BMC Genet. 2016, 17, 75. [CrossRef] [PubMed]

23. Cole, J.B.; Wiggans, G.R.; Ma, L.; Sonstegard, T.S.; Lawlor, T.J., Jr.; Crooker, B.A.; Tassell, C.P.V.; Yang, J.; Wang, S.; Matukumalli, L.K.; et al. Genome-wide association analysis of thirty one production, health, reproduction and body conformation traits in contemporary U.S. Holstein cows. BMC Genom. 2011, 12, 408. [CrossRef] [PubMed]

24. Raven, L.A.; Cocks, B.G.; Hayes, B.J. Multibreed genome wide association can improve precision of mapping causative variants underlying milk production in dairy cattle. BMC Genom. 2014, 15, 62. [CrossRef]

25. Jing, L.; Boeren, S.; Hooijdonk, T.V.; Vervoort, J.; Hettinga, K. Effect of the DGAT1 K232A genotype of dairy cows on the milk metabolome and proteome. J. Dairy Sci. 2015, 98, 3460-3469.

26. Schultz, G.; Rotatori, D.S.; Clark, W. EGF and TGF- $\alpha$ in Wound Healing and Repair. J. Cell. Biochem. 1991, 45, 346-352. [CrossRef]

27. Hemmati, A.A.; Larki-Harchegani, A.; Shabib, S.; Jalali, A.; Rezaei, A.; Housmand, G. Wound healing property of milk in full thickness wound model of rabbit. Int. J. Surg. 2018, 54, 133-140. [CrossRef]

28. Katie, A.; Cohen-Fix, F.; Cohen-Fix, O. The metaphase to anaphase transition A case of productive destruction. Eur. J. Biochem. 1999, 263, 14-19.

29. Friedl, P. Prespecification and plasticity: Shifting mechanisms of cell migration. Cell Biol. 2004, 16, 14-23. [CrossRef]

30. Friedl, P.; Wolf, K. Tumour-cell invasion and migration: Diversity and escape mechanisms. Nat. Rev. Cancer 2003, 3, 362-374. [CrossRef]

31. Yue, P.Y.K.; Leung, E.P.Y.; Mak, N.K.; Wong, R.N.S. A Simplified Method for Quantifying Cell Migration/Wound Healing in 96-Well Plates. J. Biomol. Screen. 2010, 15, 427-433. [CrossRef] [PubMed]

32. Jouanneau, J.; Thiery, J.P. Encyclopedia of Cancer, 2nd ed.; Tumor Cell Motility and Invasion Chapter; Academic Press: Cambridge, MA, USA, 2002; pp. 467-473.

33. Caliari, S.R.; Harley, B.A.C. Comprehensive Biomaterials, Biologically Inspired and Biomolecular Materials chapter. ScienceDirect 2011, 2, 279-302.

34. Banabazi, M.H.; Javaremi, A.N.; Imumorin, I.G.; Ghaderi-Zefrei, M.; Miraei Ashtiani, S.R. Single nucleotide polymorphisms (SNP) on transcriptome of Holstein cows shared with Illumina bovine SNP arrays. Online J. Vet. Res. 2016, 20, 177-182. 